\title{
«БЛАГОТВОРИТЕЛЬНОЕ» МОШЕННИЧЕСТВО: ПОНЯТИЕ, ПРИЧИНЫ ВОЗНИКНОВЕНИЯ И СПОСОБЫ ПРОФИЛАКТИКИ
}

\author{
(c) 2019 Идрисов Хусейн Вахаевич \\ кандидат юридических наук, доцент кафедры гражданского права и процесса \\ Чеченский государственный университет, Чеченская Респ., Грозный \\ E-mail: huseyn23@rambler.ru \\ (c) 2019 Гайтамирова Асет Адамовна \\ студент-магистрант юридического факультета \\ Чеченский государственный университет, Чеченская Респ., Грозный \\ E-mail: nevajno_0095@mail.ru
}

Статья посвящена краткой истории зарождения благотворительности в России и правовому анализу понятия и механизма правового регулирования благотворительной деятельности. В статье на основе исследования преступлений мошеннической направленности в сфере благотворительности характеризуются и оцениваются различные аспекты уголовно-правовых деяний в указанной сфере, рассматриваются некоторые меры, направленные на профилактику и противодействие мошенническим действиям в благотворительной деятельности.

Ключевые слова: благотворительность, мошенничество, помощь, милосердие, сострадание, уголовно-правовые отношения, правовое регулирование.

На современном этапе развития российского государства активно развивается институт благотворительной деятельности как проявление становления гражданского общества и создаются предпосылки для её более широкого распространения. Как и любая сфера деятельности она нормативно урегулирована. Прежде всего речь идет о Федеральном законе от 11 августа 1995 года № 135-Ф3 «О благотворительной деятельности и добровольчестве (волонтерстве)» (далее - ФЗ № 135) [3], в котором установлены правовые рамки и формы благотворительной деятельности благотворительных организаций. Помимо ФЗ № 135, некоторые вопросы рассматриваемой деятельности регламентируются ГК РФ, НК РФ, Федеральным законом от 12 января 1996 года № 7-Ф3 «О некоммерческих организациях» (далее - Закон о НКО) [4] и региональным законодательством субъектов РФ.

В соответствии со ст. 1 ФЗ № 135 благотворительная деятельность понимается как «добровольная деятельность граждан и юридических лиц, которая направлена на бескорыстную (безвозмездную, на льготных условиях) передачу имущества, в том числе и денежных средств, бескорыстное выполнение услуг, оказание другой поддержки гражданам или юридическим лицам, нуждающимся в помощи» [3].

Понятие «благотворительность» или филан- тропия имеет греческое происхождение (от греч. «филантропос» - «человеколюбие», «сострадание», «сердечное участие, помощь обездоленным»).

Не требует доказательства тот факт, что даже в самом благополучном государстве, всегда имеются лица, нуждающиеся в помощи, благотворительности и социальной поддержке. История развития социума свидетельствует, что в тех или иных формах, благотворительность в обществе присутствовала всегда. Благотворительность в её современном понимании появилась в конце XVIIвека, когда в ряде европейских государств были приняты первые законодательные акты о помощи неимущим. Сегодня исходным смыслом благотворительности является помощь неимущим и обездоленным [8, с. 27].

В истории российского государства изначально благотворительность существовала в качестве попечительства и помощи увечным, неимущим, сирым и престарелым. В качестве благотворительных организаций в России осуществляли деятельность бесплатные столовые, приюты для разных категорий населения, ночлежки, богадельни.

В период СССР государство полностью взяло под патронаж все вопросы благотворительной деятельности, при этом, само понятие «благотворительность» приобрело негативный смысл, 
а частная инициатива в этой сфере была нивелирована, в силу того, что советская идеология не предусматривала такие проявления, как жалость и забота об обездоленных, которые считались унизительными для советского человека, строителя коммунистического общества. Советское государство было полностью патерналистским, что исключало любые виды благотворительности, а командно-административная экономика, предполагающая равенство советских граждан, исключала возможность гражданам быть меценатами или спонсорами.

Ситуация в сфере благотворительности начала изменяться только в период «перестройки» в середине 80-х годов прошлого века, когда начали возрождаться традиции благотворительной деятельности, следствием чего и стало принятие ранее упомянутого ФЗ № 135, а затем и Закона о НКО, которые изначально сформировали правовую базу для деятельности некоммерческих благотворительных организаций в новой России.

При этом сфера благотворительности сегодня - это область деятельности, в которой имеется множество проблем и неразрешимых противоречий, которые затрудняют процесс помощи населению, нуждающемуся в помощи (малообеспеченные семьи, инвалиды, нетрудоспособные и др.) [13, с. 7].

Благотворительная деятельность в России выступает в самых разнообразных формах [15, c. 7] и представляет собой сложную систему, которую можно представить в качестве совокупности определенных, разнонаправленных структур и элементов, представленных на схеме 1.

Вместе с тем, с самого момента зарождения благотворительности как социального явления, эту сферу неустанно сопровождают и криминальные проявления, прежде всего мошенничество. Необходимо указать, что феномен мошенничества имеет давнюю историю, оно зародилось с появлением товарообмена, когда злоумышленники пытались извлечь максимальную выгоду для себя посредством обманных действий. С развитием государственности отмечается и рост преступлений мошеннической направленности. Безусловно, что законодатель всегда стремился повышать эффективность мер, направленных на пресечение подобных деяний, прежде всего увеличивая количество норм об ответственности за преступления мошеннической направленности и стараясь оптимизировать их, что доказывает высокий уровень распространенности этих деяний. В современный период актуальность противодействия такому преступному деянию как мошенничество имеет тенденцию к все большему возрастанию.

Исследователи этого явления отмечают исключительную многообразность проявления

\section{СИСТЕМА БЛАГОТВОРИТЕЛЬНОСТИ В РОССИИ}

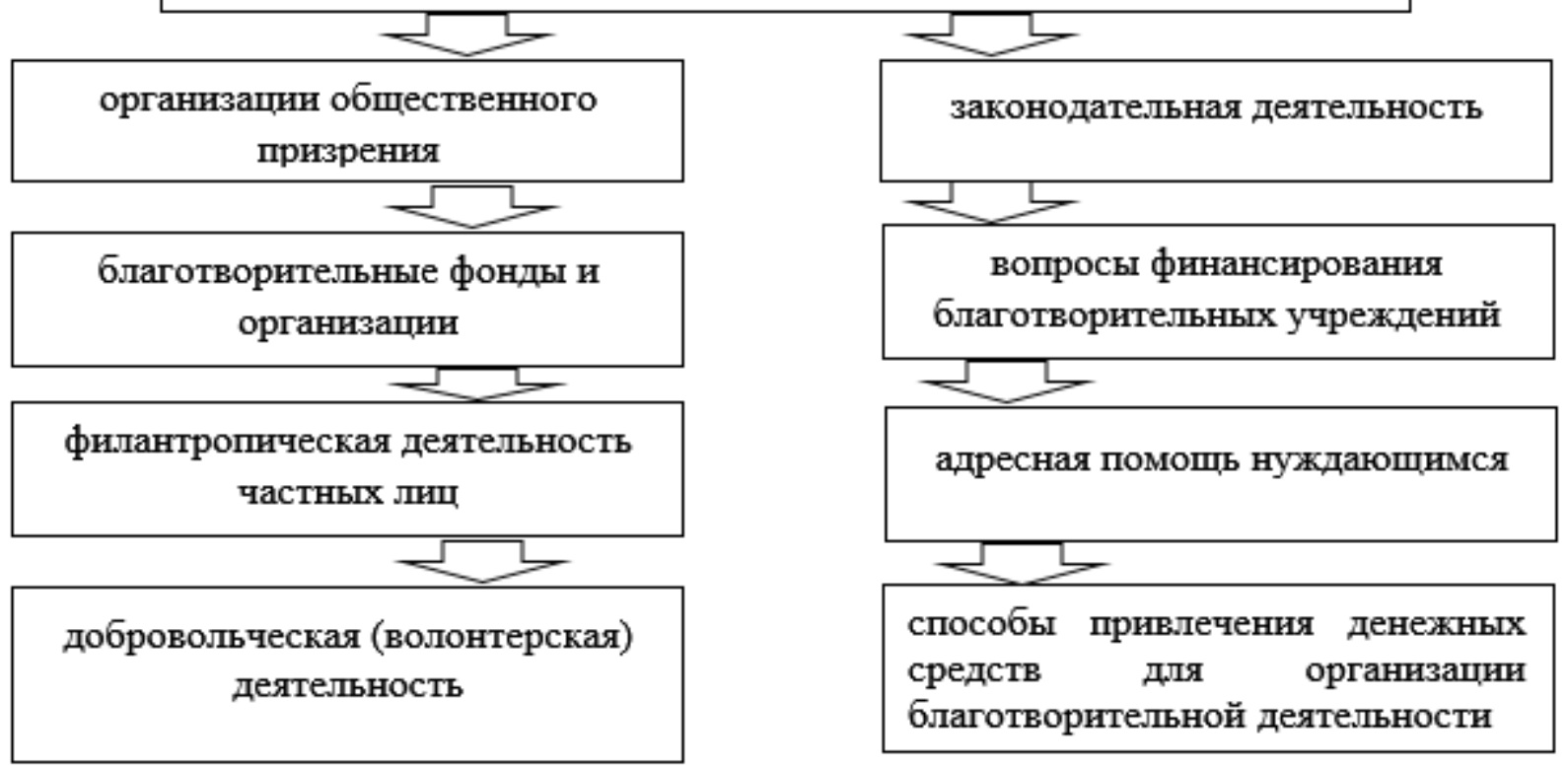

Схема 1 Элементы благотворительной деятельности в России [11]. 
мошенничества в самых различных сферах жизнедеятельности российского общества [14, с. 412]. Не является исключением и сфера благотворительности. Современные мошенники отличаются высоким уровнем адаптивности, способностью к модернизации мошеннических деяний, немалой смекалкой и общим уровнем интеллектуального развития. Этому в значительной степени способствуют и современные научнотехнические достижения, прежде всего в сфере коммуникативных технологий, в частности широкое развитие интернет-технологий. Также к факторам, способствующим развитию явления мошенничества, можно отнести и возрастающие темпы экономического роста, активная эволюция института собственности, возрастание числа договорных отношений. При этом, новые формы приобретает человеческое общение, которое компьютеризируется и интегрируется. И если ранее, мошенники были вынуждены реализовывать свои замыслы, тратя на подготовку довольно длительное время, то сегодня, для того чтобы достичь аналогичного результата необходимо значительно меньше времени и ресурсов.

Статистические данные ГИАЦ МВД показывают, что несмотря на отдельные колебания в показателях по годам, количество зарегистрированных мошеннических действий в РФ по-прежнему имеет устойчивую положительную динамику. Так, в период с 2015 по 2018 год количество преступлений мошеннической направленности в России возросло с порядка166 тысяч до 222 тысяч зарегистрированных преступлений. При этом, раскрываемость данных преступлений постоянно снижается: с 36\% до текущих 17\% от общего числа зарегистрированных и переданных в суд дел. Относительно всех зарегистрированных преступлений, доля преступлений мошеннической направленности в среднем остается стабильной и составляет около $6 \%$ [12]. Данный вид преступлений наносит значительный ущерб не только имуществу частных лиц, но и государству в целом. При этом специалисты отмечают и высокий уровень латентности, что обусловлено скрытым характером самого деяния.

Как правило, в качестве субъекта преступления мошеннической направленности выступают не маргинальные элементы - бродяги, алкоголики, безработные. Чаще всего в качестве организаторов мошеннических действий выступают лица имеющие достаточный уровень образова- ния, жизненный опыт [9, с. 128]. Это опосредует необходимость более качественного конструирования норм, предусматривающих ответственность за мошенничество. На сегодняшний день среди теоретиков, также, как и среди юристовпрактиков, отсутствует единство мнений по поводу трактовки видовой принадлежности и непосредственного объекта этого преступления, недостаточно четко определяется и вопрос о том, что следует относить к предмету мошенничества. Имеются и отдельные трудности по поводу характеристики состава преступлений мошеннической направленности, которые совершаются посредством приобретения права на чужое имущество. Отсутствует единство в понимания корыстной цели. В среде юридической общественности все чаще раздаются призывы о снижении возраста уголовной ответственности за мошенничество и т.д. Действительно, современная уголовно-криминальная практика подтверждает необходимость оптимизации уголовного законодательства в сфере противодействия мошенническим действиям.

В ст. 159 УК РФ [1], законодатель приводит дефиницию мошенничества, которая сформировалась еще в советский период, однако переход России на рыночные отношения потребовал переосмысления данного преступного деяния, с целью учета изменившихся социально-экономических условий и появления новых общественных отношений, не существовавших раннее. Для разрешения отдельных проблем был принят ФЗ от 29 ноября 2012 г. № 207Ф3 «О внесении изменений в Уголовный кодекс Российской Федерации и отдельные законодательные акты Российской Федерации» [2]. В частности, законодателем была дифференцирована ответственность за мошенничество в зависимости от сферы деяния (ст. 159.1-159.6 УК РФ).

Что касается мошенничества в сфере благотворительности, то сегодня всё большее распространение получают разновидности мошеннических деяний, которые совершают профессиональные преступники в этой области, так называемые «сборщики», которые под видом сбора средств на благотворительность занимаются криминальным обманом. При этом, за исполнителями данных преступных деяний стоят хорошо организованные группы мошенниковпрофессионалов. Общеизвестно, что, реализуя криминальный замысел в благотворительной сфере, мошенники пытаются влиять прежде все- 
го на положительные качества личности потенциальной жертвы [6, с. 110]. Для этого разрабатываются специальные мошеннические сценарии, направленные на то, чтобы вызвать у потенциальной жертвы чувства сострадания и желания помочь нуждающимся. Разновидностей мошенничества в сфере благотворительности множество, но все они ведут к таким негативным последствиям, которые состоят в том, что люди, которые действительно оказались в трудной жизненной ситуации и нуждаются в помощи не получают ее или получают в меньшем объеме, в связи с тем, что потенциальные благотворители перестают реагировать на призывы о помощи [7, c. 66].

Представители теоретических кругов на основе эмпирических исследований фактов мошенничества в благотворительной сфере в качестве основной причины называют значительную имущественную дифференциацию в социальной структуре общества, которая в итоге опосредует антиобщественную направленность личности, которая пытается криминальными способами повысить уровень собственного благополучия $[10$, с. 76]. Таким образом, лица, склонные к девиантному поведению, не имея возможности удовлетворить возрастающие материальные потребности законным путем, прибегают к преступным способам их удовлетворения. При этом, противоречия между потребностями и возможностями их удовлетворения являются основной причиной корыстного мотива, который лежит в основе мошенничества. И именно благотворительность становится для таких лиц сферой наименьшего сопротивления для достижения корыстных целей.

В качестве условий, которые способствуют совершению мошеннических деяний в сфере благотворительности выступает целый комплекс негативных явлений, к которым относятся, прежде всего смена ценностных критериев, характерных для периодов политической и экономической нестабильности, корысть, предрасположенность к обману и др.

Наибольшее распространение в современный период в благотворительной сфере получили мошеннические деяния по незаконному получению денежных средств обманным путем. Недобросовестные предприниматели при помощи мошеннических действий регистрируют лжефонды, открывают счета в банках, получают и выдают незаконные кредиты, приобретают по поддельным документам партии товаров, продают не принадлежащее им имущество.

Зачастую, мошенники, выдавая себя за ответственных должностных лиц, руководителей и представителей благотворительных фондов и иных организаций, входят в доверие к гражданам, юридическим лицам, государственным органам, реализуют разработанную мошенническую схему и заключают сделки, направленные на получение прибыли для собственных нужд, приобретают те или иные имущественные блага. При этом мошенники используют документы и бланки, заверенные фальсифицированными подписями, печатями и штампами. Известны случаи использования подложных финансовых поручительств и гарантийных писем.

Все большее распространение получает и такой приём как «клонирование» добросовестных благотворительных организаций. В таких случаях, под прикрытием бренда известного фонда, мошенники собирают средства для собственных нужд. Данные статистики свидетельствуют о том, что ущерб, причиненный мошенниками в некоторых случаях, сопоставим с ущербом от последствий краж, грабежей и других видов хищений [5, с. 178].

Следует обратить внимание и на появление в практике новых мошеннических действий, не укладывающихся в рамки действующего УК РФ. Например, интернет-мошенничества, когда лжеблаготворители собирают средства на лечение людей, чаще всего детей, не существующих в природе, или на финансирование несуществующих благотворительных организаций, для проведения мифических мероприятий, концертов, выставок и др. [16, с. 133].

Также мошенники создают копии сайтов, реально действующих и широко известных благотворительных фондов лишь с одним отличием - номером расчетного счета. При этом на этих сайтах могут публиковаться реальные фотографии и личные данные лиц, детей, которые действительно нуждаются в лечении или оказались в трудной жизненной ситуации, но средства, получаемые для помощи им, присваиваются мошенниками.

Активно используются для мошеннических схем в сфере благотворительности и аккаунты в известных социальных сетях («Одноклассники», «ВКонтакте», «Instagram», «Facebook»), где создаются фальшивые группы, в которых копируется информация из официальных групп, но предо- 
ставляются фальшивые реквизиты для перечисления денег на номера электронных кошельков и собственных банковских карт.

Темпы научно-технического прогресса возрастают так быстро, что законодатель не успевает оперативно реагировать на появление новых видов преступлений, что вызывает трудности квалификации преступлений, то есть возникает коллизия, при которой противоправное деяние совершается, а соответствующей квалифицирующей статьи в УК РФ не имеется.

Для профилактики мошенничества в сфере благотворительности необходимо прежде всего исключить возможность неправильной квалификации и установления признаков, характеризующих мошенничество. Следует также минимизировать условия и причины совершения мошенничеств в благотворительности с учетом того, что мошенничество в сфере благотворительной деятельности наносит не только финансовый, но и моральный ущерб обществу [6, с. 110].

Полагаем, что мошенничество в благотворительности должно быть отнесено к категориям преступлений, имеющих повышенную социальную опасность, так как зачастую, обманутые жертвователи, лишившись своих сбережений во имя благотворительности, утрачивают доверие и к другим членам общества, и в будущем отказываются участвовать в любой благотворительной деятельности. Поэтому, правы авторы, отстаивающие позицию, согласно которой, отношение законодателя к мошенничеству в сфере благотворительности должно быть ужесточено, посредством внесения соответствующих изменений в УК РФ.

Следует отметить и такую проблему, как отсутствие четкого закрепления в законодательстве критериев для определения статуса малообеспеченного или социально незащищенного лица. Именно поэтому не вполне понятно, помощь какой группе лиц является благотворительностью. Также негативным явлением можно признать отсутствие должного государственного контроля за благотворительной деятельностью [5, с. 178]. Не осуществляется официальный мониторинг средств, которые представители бизнеса вкладывают в благотворительность, не транслируется положительный опыт в этой сфере, недостаточно информации об экономическом или социальном эффекте подобной деятельности, которая должна на постоянной основе размещаться в самых разнообразных СМИ.

В качестве проблем также можно выделить и то, что отсутствует отслеживание нецелевого использования гуманитарной помощи, неясны защитные механизмы, используемые государственными органами для предотвращения использования благотворительной деятельности в корыстных интересах. И главное, отсутствует контролирующий государственный орган, который был бы уполномочен регулировать и контролировать осуществление и развитие благотворительной деятельности [8, с. 28].

Помимо указанных проблем мошенничества в сфере благотворительной деятельности по отношению к организациям имеются и проблемы более узкого характера, которые также требуют разрешения. Это вопросы частной или личной благотворительности. Не секрет, что сегодня большая часть просящих помощи - это профессиональные попрошайки, в связи с этим возникает вопрос о личной ответственности каждого в принятии решения о взаимопомощи. Следует четко понимать, что, подавая профессиональным попрошайкам, человек напрямую финансирует криминальную среду. Мошенничество такого рода осуществляется четко организованными структурами, включающими ряд лицучастников, и поэтому, отдельные исследователи относят эту категорию профессиональных попрошаек к организованной преступности. При наличии сомнения относительно конкретноопределенного «просящего», при наличии желания оказать помощь, следует удостовериться в том, что это лицо действительно нуждается и это подтверждается документально. Следует понимать, что люди, которые действительно нуждаются в помощи, чаще всего обращаются за помощью в благотворительные фонды, к организаторам акций и сборов денежных средств на законных основаниях.

В заключении констатируем, что милосердию всегда должно быть место в нашей жизни, но оно не должно быть направлено на поддержку «благотворительного» мошенничества. 


\section{Библиографический список}

1. Уголовный кодекс Российской Федерации от 13 июня 1996 г. № 63-Ф3 в ред. от 2 августа 2019 г.: принят Гос. Думой Федер. Собр. Рос. Федерации 24 мая 1996 г.: одобр. Советом Федерации Федер. Собр. Рос. Федерации5 июня 1996 г.//Собрание законодательства РФ. 1996. № 25. Ст. 2954.

2. «О внесении изменений в Уголовный кодекс Российской Федерации и отдельные законодательные акты Российской Федерации»: федеральный закон от 7 декабря 2011 г. № 420-Ф3 в ред. от 3 июля 2016 г.: принят Гос. Думой Федер. Собр. Рос. Федерации 17 ноября 2011 г.: одобр. Советом Федерации Федер. Собр. Рос. Федерации29 ноября 2011 г.//Собрание законодательства РФ. 2011. № 50. Ст. 7362.

3. «О благотворительной деятельности и добровольчестве (волонтерстве)»: федеральный закон от 11 августа 1995 г. № 135-ФЗ в ред. от 18 декабря 2018 г.: принят Гос. Думой Федер. Собр. Рос. Федерации 7 июля 1995 г.// Собрание законодательства РФ. 1995. № 33. Ст. 3340.

4. «О некоммерческих организациях»: федеральный закон от 12 января 1996 г. № 7-ФЗ в ред. от 29 июля 2018 г.: принят Гос. Думой Федер. Собр. Рос. Федерации 8 декабря 1995 г. //Собрание законодательства РФ. 1996. № 3. Ст. 145.

5. Антонов И.О. Особенности выявления случаев мошенничества, совершенных при сборе средств на благотворительные цели в информационно-телекоммуникационной сети «Интернет» // Вестник ВУиТ. 2012. № 2 [76). С. 177-182.

6. Берзина Н.Г. Благотворительность в России: уголовно-правовой аспект // ВестникСанкт-Петербургской юридической академии. 2016. № 1. С. 109-112.

7. Возмилкина Е.Н. Институт благотворительности в России: истоки, современность и перспективы развития //Новая наука: Стратегии и векторы развития. 2015. № 5-2. С. 65-68.

8. ердева Н.И. Преступления, совершаемые под видом благотворительной деятельности // Российский следователь. 2005. № 5. С. 27-33.

9. Ищук Т.В. Контроль за благотворительной деятельностью и правонарушения в области благотворительной деятельности в Российской Федерации // Право: современные тенденции: материалы III Междунар. науч. конф. [г. Краснодар, февраль 2016 г.).- Краснодар: Новация, 2016. С. 127-129.

10. Кузнецов А.П. Ответственность за специальные виды мошенничества: проблемы квалификации и разграничения со смежными составами // Преступления в сфере экономики: российский и европейский опыт: материалы совместного российско-германского круглого стола.-М., МГЮА. 2014. С. 75-85.

11. Панфилова T.M., Свекровкина Е.А. Формирование системы института благотворительности в России // Материалы V Международной студенческой научной конференции «Студенческий научный форум» URL: https://scienceforum.ru/2013/article/2013003712 (дата обращения: 25.09.2019).

12. Статистика и аналитика. Состояние преступности. Официальный сайт Министерства внутренних дел Российской Федерации. URL: https://мвд.pф/folder/101762 (дата обращения: 25.09.2019).

13. Тельных В.С., Шахназарян Б.А. Основные проблемы благотворительности в России и пути их решения // Таврический научный обозреватель. 2016. № 1-2 (6). С. 6-8

14. Филатова Я.С. Благотворительность сегодня: проблемы и перспективы /В сборнике: Социальная работа в современном мире: взаимодействие науки, образования и практики материалы VII международной научно-практической конференции. 2015. С. 410-413.

15. Хорева Л.В. История благотворительности в России: учеб. пособие / Л.В. Хорева, М.Д. Сущинская. СПб.: СПГУЭФ, 2009. $196 \mathrm{c.}$

16. Шхагапсоев 3. Л., Тутуков А.Ю. Особенности выявления мошенничества в сфере компьютерной информации // Социально-политические науки. 2018. № 1. С. 132-134. 